American Journal of Pharmaceutical Education 2021; 85 (3) Article 8179.

\title{
BRIEF
}

\section{Trends in Pharmacy College Admission Test Requirements and Utilization Across Colleges and Schools of Pharmacy}

Jamie L. Hall, PharmD, ${ }^{a}$ Robin L. Corelli, PharmD, ${ }^{b}$ Renee DeHart, PharmD, ${ }^{c}$ Jason Haney, PharmD, ${ }^{d}$ Lisa Lebovitz, JD, ${ }^{\mathrm{e}}$ Ann M. Philbrick, PharmD, ${ }^{\mathrm{f}}$ Libby J. Ross, MA, ${ }^{\mathrm{g}}$ Caroline Sierra, PharmD, ${ }^{\mathrm{h}}$ Paul Jungnickel, $\mathrm{PhD}^{\mathrm{i}}$

${ }^{a}$ University of Missouri Kansas City, School of Pharmacy at MU, Columbia, Missouri

${ }^{\mathrm{b}}$ University of California, San Francisco School of Pharmacy, San Francisco, California

${ }^{c}$ Samford University McWhorter, School of Pharmacy, Birmingham, Alabama

${ }^{\mathrm{d}}$ Medical University of South Carolina, College of Pharmacy, Charleston, South Carolina

${ }^{\mathrm{e}}$ University of Maryland, School of Pharmacy, Baltimore, Maryland

${ }^{\mathrm{f}}$ University of Minnesota, College of Pharmacy, Minneapolis, Minnesota

${ }^{g}$ American Association of Colleges of Pharmacy, Arlington, Virginia

${ }^{\mathrm{h}}$ Loma Linda University, School of Pharmacy, Loma Linda, California

${ }^{\mathrm{i}}$ Auburn University Harrison School of Pharmacy, Auburn, Alabama

Submitted May 21, 2020; accepted November 30, 2020; published March 2021.

Objective. To identify national trends among US pharmacy schools and colleges in their requirements for the Pharmacy College Admission Test (PCAT) and underlying rationales for not requiring pharmacy school applicants to take it.

Methods. An electronic survey regarding the following was sent to all US pharmacy programs: current and future PCAT requirements for applicants, use of the PCAT or other means to assess applicants' written communication skills, use of unofficial PCAT scores, and, if applicable, the rationale for not requiring applicants to submit PCAT scores. Data analysis was performed using Excel.

Results. One hundred five (73\%) of 144 schools and colleges of pharmacy responded to the survey. Twelve institutions discontinued the PCAT requirement between the 2018-2019 and 2019-2020 admissions cycles. The most commonly selected reason for discontinuation was a desire to increase pharmacy applications by reducing admission barriers. Pharmacy schools nationwide had concerns regarding high PCAT registration fees. The majority of pharmacy programs that used PCAT scores in their application process indicated that they always, often, or sometimes invited applicants for an interview before they had received the applicant's official PCAT scores. The majority of pharmacy programs considered applicants' PCAT writing score in making their admissions decisions. Other methods used included onsite essays and personal statements.

Conclusion. At the time of this study the majority of US pharmacy schools required applicants to submit the PCAT scores before being considered for admission to pharmacy school; however, the use of this examination has declined nationally.

Keywords: pharmacy college admissions test, admissions, assessment, student pharmacists

\section{INTRODUCTION}

The Pharmacy College Admission Test (PCAT) is a standardized test designed for and administered to prospective pharmacy students by the Pearson Corporation. The objective of the examination is to measure a

Corresponding Author: Jamie Hall, University of Missouri Kansas City, School of Pharmacy at MU, 812 Lewis Hall, Columbia, MO 65201. Tel: 573-884-9679.Email: halljamie@ umkc.edu candidate's academic preparation for pharmacy school. For many years, most Doctor of Pharmacy programs in the United States used applicants' PCAT scores in their assessment of applicants for admission to pharmacy school. In recent years, there has been a decline in the number of institutions requiring applicants to submit PCAT scores to be considered for admission. Reasons for schools discontinuing the PCAT requirement for admission vary and previously have only been reported anecdotally. 


\section{American Journal of Pharmaceutical Education 2021; 85 (3) Article 8179.}

The PCAT Advisory Committee, appointed by the President of the American Association of Colleges of Pharmacy (AACP) and comprised of AACP staff and members representing various pharmacy programs, was charged with advising AACP and the Pearson Corporation regarding the development, administration, and promotion of the PCAT. The committee was also asked to assist in the enhancement of the examination to ensure it effectively predicts the academic preparedness of pharmacy applicants. The committee conducted a nationwide survey of schools and colleges of pharmacy to identify current usage of and national trends related to the PCAT, and to characterize the rationales of those schools that have eliminated the PCAT admission requirement.

\section{METHODS}

The AACP PCAT Advisory Committee developed a 13-item survey that contained questions in the following content areas: current and future PCAT requirements for admission, use of the PCAT or other means to assess applicants' written communication skills, institutional concerns about the cost of the PCAT, use of unofficial PCAT scores during the admission process, and reasons for not requiring the PCAT as an admissions requirement (this question was only asked of institutions not requiring the PCAT). ${ }^{1}$

The survey, available at https://bit.ly/2EypFye, was administered electronically using the Formsite.com platform. A link to the survey was sent via the AACP Connect member communication portal in May 2019 to the online communities for PharmCAS, the Student Services Personnel special interest group (SIG), and members of the Council of Deans, which represents all US pharmacy programs ( $n=144$ as of 2019 when the survey was disseminated). ${ }^{1}$ Instructions in the recruitment email specified that only individuals knowledgeable about the use of the PCAT at their institution (eg, admissions director, admissions committee chair) should complete the survey. Two reminder emails were sent during the following month.

The AACP staff obtained institutional demographic data (ie, institution type, year founded, geographic region) and merged that data with the PCAT survey responses to create a de-identified data set. Programs were categorized as "established" (founded before 1996) or "newer" (founded in 1996 or later) to reflect the year when there was a substantial increase in the number of pharmacy programs in the United States. ${ }^{2,3}$ Responding programs were characterized by the Federal Trade Commission's geographic regions, ${ }^{4}$ and then grouped into four sections based on location (Midwest, Northeast,
South, and West). Data analysis was conducted using Microsoft Excel. Responses of "not sure" and "not applicable" were removed from descriptive calculations.

\section{RESULTS}

One hundred five $(73 \%)$ of the 144 accredited US pharmacy programs responded to the survey. A slight majority of respondents were from public institutions (57/ 105, 54\%) and institutions founded before 1996 (56/105, $53 \%$ ). Of the institutions that responded to the survey, 24 schools were located in the Midwest, 27 in the Northeast, 29 in the South, and 25 in the West. The breakdown of programs requiring applicants to take the PCAT (reported by region and institution type) is depicted in Table 1. Of the 76 institutions that required applicants to submit PCAT scores for admission in 2018-2019, four stopped requiring it for the 2019-2020 school year and eight were undecided about whether to require it at the time of the survey. These 12 institutions were comprised of three private and nine public pharmacy schools. Seven of the 12 were established before 1996 and five in 1996 or later. Three of the 12 schools were located in the Midwest, four in the Northeast, two in the South, and three in the West.

Twenty-nine institutions (18 private, 17 newer) that did not require or no longer required the PCAT indicated the reasons for this decision by selecting from a list of options (multiple selections were allowed). A "desire to increase pharmacy applications by reducing admissions barriers" was the most commonly selected choice (21/29, $72 \%$ ). The majority of programs selecting this response were newer institutions $(13 / 21,62 \%)$, private institutions $(12 / 21,57 \%)$, and institutions located in the West $(9 / 21$, $43 \%$ ). The response "Our analysis indicates PCAT is not a strong predictor of success for our students" was selected by 15 programs; of these, $10 / 15,67 \%$, were private pharmacy schools. The response "Other colleges/schools in my region do not (or no longer) require the PCAT" was also chosen by 15 institutions. These programs were more likely to be newer $(10 / 15,67 \%)$, private $(10 / 15,67 \%)$, and located in the West $(8 / 15,53 \%)$. The full list of questions and breakdown of responses are presented in Table 2 .

The PCAT registration fee was a perceived application barrier by most institutions. Most respondents (81/ $105,77 \%$ ) agreed or strongly agreed that the cost of the PCAT may prevent low-income students from taking the examination and thus applying to their program if they required students to submit PCAT scores. This was a more common sentiment among public institutions (47/57 or $82 \%$ agreed or strongly agreed with this item) than private (34/48 or $71 \%$, agreed or strongly agreed with this item). Concern that payment of the registration fee for taking the 


\section{American Journal of Pharmaceutical Education 2021; 85 (3) Article 8179.}

Table 1. Pharmacy College Admission Test Requirements for Academic Years 2018-2019 and 2019-2020

\begin{tabular}{|c|c|c|c|c|c|c|}
\hline & \multicolumn{3}{|l|}{$\begin{array}{c}\text { All } \\
\text { Schools }\end{array}$} & \multicolumn{3}{|c|}{$2019-20(n=105)$} \\
\hline & $\begin{array}{l}2018, \\
\text { n }(\%)\end{array}$ & $\begin{array}{l}\text { Required, }^{a} \\
\text { n (\%) }\end{array}$ & $\begin{array}{c}\text { Not } \\
\text { Required, } \\
\text { n (\%) }\end{array}$ & $\begin{array}{l}\text { Required, }^{a} \\
\text { n }(\%)\end{array}$ & $\begin{array}{c}\text { Not } \\
\text { Required, } \\
\text { n }(\%)\end{array}$ & $\begin{array}{c}\text { Undecided, } \\
\text { n (\%) }\end{array}$ \\
\hline All Schools & 144 & $76(72)$ & $29(28)$ & $64(61)$ & $33(31)$ & $8(8)$ \\
\hline \multicolumn{7}{|l|}{ Age of Program } \\
\hline $\begin{array}{l}\text { Founded before } \\
1996\end{array}$ & $66(46)$ & $45(80)$ & $11(20)$ & $38(68)$ & $15(27)$ & $3(5)$ \\
\hline \multicolumn{7}{|l|}{ Status } \\
\hline Private & $76(53)$ & $27(56)$ & $21(44)$ & $24(50)$ & $21(44)$ & $3(6)$ \\
\hline South $^{f}$ & $41(28)$ & $22(76)$ & $7(24)$ & $20(69)$ & $8(28)$ & $1(3)$ \\
\hline West $^{\mathrm{g}}$ & $30(21)$ & $12(48)$ & $13(52)$ & $9(36)$ & $15(60)$ & $1(4)$ \\
\hline \multicolumn{7}{|c|}{$\begin{array}{l}\text { Required for all applicants, OR required for some applicants but not all } \\
\text { b } \text { Accepted and considered but not required, OR Not required nor considered } \\
{ }^{\mathrm{c}} \text { Excludes Lebanese American University; denominator for this group is } 143 \\
\text { d Includes IA, IL, IN, KS, KY, MO, MN, ND, NE, SD, WI } \\
\text { e Includes CT, DC, DE, MA, MD, ME, MI, NH, NJ, NY, OH, PA, PR, RI, VA, VT, WV } \\
\text { I Includes AL, AR, FL, GA, LA, MS, NC, NM, OK, SC, TN, TX } \\
\text { g Includes AK, AZ, CA, CO, HI, ID, MT, NV, OR, UT, WA, WY }\end{array}$} \\
\hline
\end{tabular}

PCAT was a deterrent for low-income applicants was high nationwide: 81 programs agreed or strongly agreed vs 12 programs that disagreed and 12 that selected not applicable. Regional competition was also a concern: 83 programs agreed or strongly agreed the PCAT registration fee may prevent students from applying to their institution if other programs in their region did not require the examination, versus only six programs that disagreed and 15 that reported not applicable. This concern was evenly shared among private $(36 / 83,43 \%)$ and public institutions (47/83, 57\%) and among newer (37/83, 45\%) and established programs $(48 / 83,55 \%$,), and across institutions in different geographic regions (22/83, 27\% Northeast; 20/83, 24\% Midwest; 17/83, 20\% West; 24/83, 29\% South).

The majority $(60 / 84,71 \%)$ of programs that use PCAT scores in their pharmacy school application process either always, often, or sometimes invited applicants for an interview before receiving the applicant's official PCAT score. This practice was most common among private institutions and in the Northeast. Acceptance of a candidate prior to receiving their official PCAT score was more common among private institutions and in the South. Once applicants were admitted, 23 institutions (12 private, 11 public) used PCAT scores to identify at-risk students who might benefit from early intervention to avoid academic struggles. Only one school in the West used PCAT scores in this way, compared to five in the Midwest, seven in the Northeast, and 10 in the South.

Of the 48 institutions that reported considering the PCAT writing score for admissions decisions, nearly $70 \%$ $(33 / 48)$ were public. By region, it was least used in the West (only four programs, all public). Eighteen of the 48 programs (38\%) used it to meet the requirement set forth by the Accreditation Council for Pharmacy Education (ACPE) to assess written communication in the admissions process. All respondents were also asked what other methods they used to fulfill this requirement: $60 \%(63 / 105)$ required an onsite essay during the interview process (34 private and 29 public). Only 28 programs reported using the personal statement from the Pharmacy College Application Service application as a writing sample to fulfill ACPE's applicant writing requirement.

\section{DISCUSSION}

The majority of US pharmacy programs that responded to the survey required applicants to submit a PCAT score before an admissions decision could be made; however, the number of schools that require the 
American Journal of Pharmaceutical Education 2021; 85 (3) Article 8179.

Table 2. Rationale Selected by Colleges and Schools of Pharmacy for Not Requiring the Pharmacy College Admission Test

\begin{tabular}{|c|c|c|c|c|c|c|c|}
\hline Reason & $\begin{array}{c}n=29 \\
(\%)\end{array}$ & $\begin{array}{c}<1996 \\
\mathrm{n}=17\end{array}$ & $\begin{array}{l}\geq 1996 \\
\mathrm{n}=12\end{array}$ & $\begin{array}{c}\text { Private } \\
\mathrm{n}=18\end{array}$ & $\begin{array}{c}\text { Public } \\
\text { n=11 }\end{array}$ & $\begin{array}{l}\text { West } \\
\mathrm{n}=13\end{array}$ & $\begin{array}{c}\begin{array}{c}\text { Other } \\
\text { Regions } \\
n=16\end{array} \\
\end{array}$ \\
\hline $\begin{array}{l}\text { Desire to increase pharmacy applications by } \\
\text { reducing admission barriers. }\end{array}$ & $21(72)$ & 13 & 8 & 12 & 9 & 9 & 12 \\
\hline $\begin{array}{l}\text { Other colleges/schools in my region do not } \\
\text { (or no longer) require the PCAT. }\end{array}$ & $15(52)$ & 10 & 5 & 10 & 5 & 8 & 7 \\
\hline $\begin{array}{l}\text { Our analysis indicates PCAT is not a strong } \\
\text { predictor of success for our students. }\end{array}$ & $15(52)$ & 9 & 6 & 10 & 5 & 3 & 12 \\
\hline PCAT is too expensive for applicants. & $13(45)$ & 4 & 9 & 5 & 8 & 6 & 7 \\
\hline $\begin{array}{l}\text { PCAT does not help us identify qualified } \\
\text { applicants. }\end{array}$ & $12(41)$ & 6 & 6 & 9 & 3 & 3 & 9 \\
\hline $\begin{array}{l}\text { Our perception that PCAT is not a strong } \\
\text { predictor of success. }\end{array}$ & $11(38)$ & 5 & 6 & 6 & 5 & 2 & 9 \\
\hline $\begin{array}{l}\text { Non-cognitive attributes are more heavily (or } \\
\text { solely) weighted in our admissions } \\
\text { process. }\end{array}$ & $9(31)$ & 4 & 5 & 5 & 4 & 4 & 5 \\
\hline $\begin{array}{l}\text { PCAT does not adequately assess content } \\
\text { areas. }\end{array}$ & $5(17)$ & 3 & 2 & 3 & 2 & 1 & 4 \\
\hline PCAT test dates do not meet our needs. & $4(14)$ & 4 & 0 & 3 & 1 & 2 & 2 \\
\hline PCAT scoring is too slow. & $2(7)$ & 1 & 1 & 1 & 1 & 1 & 1 \\
\hline PCAT is too long for test-takers. & $1(3)$ & 1 & 0 & 1 & 0 & 0 & 1 \\
\hline Other & $1(3)$ & 0 & 1 & 1 & 0 & 0 & 1 \\
\hline
\end{tabular}

Abbreviation: PCAT $=$ Pharmacy College Admission Test

PCAT continues to decline. ${ }^{5}$ Our data suggest that programs requiring the PCAT for admission tend to be public and established. Over one-third of private institutions, compared with approximately one-fourth of public, admit applicants to the program without receiving the applicants' official PCAT score. This suggests that pharmacy programs might be moving toward a more holistic admissions process.

More than one-quarter of respondents used an applicant's performance on the PCAT to identify students at risk of having academic difficulty in pharmacy school and who might need early intervention to ensure their success. This survey did not ascertain whether institutions use other metrics to determine which students require additional assistance, though Muratov and colleagues demonstrated that several components should be considered when making this determination. ${ }^{6}$ Using PCAT scores more holistically like this, as a metric for identifying students who need early academic intervention, may continue to be an area of utility for the PCAT, even in programs where taking the examination is no longer required for admission.

The current published evidence is mixed regarding the relationship between a student's performance on the PCAT, and their success during pharmacy school. In one retrospective study, PCAT scores were strong predictors of students' success in a pharmaceutical calculations course, and in several other studies, on the Pharmacy Curriculum Outcomes Assessment (PCOA). ${ }^{7-11}$ However, Ferrante and colleagues demonstrated that PCAT scores are not reliable indicators of students' progress during pharmacy school, and others state that PCAT scores do not predict student performance on objective structured clinical examinations or advanced pharmacy practice experiences. ${ }^{12-14}$ The lack of consensuses within literature regarding the correlation between PCAT scores and student academic success does not negate the potential predictive value of the PCAT, especially when it comes to the PCOA. This is an important point in light of the ACPE's use of the PCOA as a measure of curricular effectiveness, and the PCAT's potential to identify at-risk students for early intervention before they struggle in the curriculum or perform poorly on the PCOA. However, the unclear relationship between a students' performance on the PCAT and their academic progress, coupled with the pressure pharmacy schools are facing as they compete for new students with other regional institutions that no longer require the PCAT, may explain the survey results, which show a shift away from schools requiring applicants to take the PCAT.

One concern brought to light by this study is that some institutions perceived the cost of the PCAT as a 


\section{American Journal of Pharmaceutical Education 2021; 85 (3) Article 8179.}

barrier to students applying to their program. The majority of respondents expressed a concern about the PCAT fee, especially when other programs in their area did not require the PCAT. This is a greater concern for public institutions, the majority of which required the PCAT for admission. Additionally, while fewer than half of the responding programs in the West region did not require the PCAT for admission, their concern about the impact of the PCAT fee on applicants was not significantly different from that of institutions in other regions.

The movement away from standardized testing is not limited to pharmacy education. A growing number of law schools have announced they will accept the Graduate Record Examination in lieu of the Law School Admission Test for admission to accommodate prospective students who are exploring multiple career options. ${ }^{15-17}$ There has also been a dramatic shift in testing policies at undergraduate institutions. Between September 2018 and September 2019, nearly 50 colleges and universities announced they were dropping the Scholastic Aptitude Test or American College Testing as an admission requirement. ${ }^{18}$ Additionally, an organization claiming the standardized testing requirement violates antidiscrimination statutes within their state sued the University of California in December 2019. ${ }^{19}$ These and other environmental factors may influence an institution's decision to require the PCAT for admission.

Interestingly, 48 respondents indicated they used the PCAT writing score in their admissions decisions, but only $40 \%$ reported using the writing score to meet ACPE's requirement for assessing written communication during the admissions process. Onsite essays and use of the personal statement from the PharmCAS application were commonly reported by programs as methods used to assess applicants' writing skills. Both methods have limitations that must be considered inferior to the PCAT writing assessment. The PharmCAS essays may not be a true reflection of the applicant's writing ability since it is not monitored and there is opportunity to have someone else write or edit. Onsite writing samples increase time required for the interview as well as workload for those assessing responses. In contrast, the PCAT uses a validated system for evaluating student essays, with trained scorers using standardized processes and rubrics. A potential option for programs that only need a validated, standardized assessment of applicants' writing would be for this PCAT section to be offered as a standalone product at low cost.

\section{CONCLUSION}

While the majority of US schools and colleges of pharmacy still required the PCAT for admission to pharmacy school, the use of this examination has declined nationally. This trend seems to be driven by the decreasing applicant pool and if other schools within a region no longer require the PCAT for admission. Some programs have found additional uses for PCAT scores, such as in identifying at risk students, but further research is needed to determine the relationship between PCAT performance and student success in pharmacy school.

\section{ACKNOWLEDGMENTS}

All authors are present or past members of the AACP PCAT Advisory Committee. Paul Jungnickel serves as Chair of AACP's PCAT Advisory Committee. Libby Ross serves on the AACP staff. AACP has an agreement with Pearson in support of the PCAT.

\section{REFERENCES}

1. American Association of Colleges of Pharmacy PCAT School Survey. 2019. https://bit.ly/2EypFye. Accessed February 26, 2021. 2. Maine LL. Vlasses PH Assessing quality in pharmacy education in an era of rapid expansion. $J$ Am Pharm Assoc. 2012;52(4):528-534. 3. Knapp DA, Knapp DE. Attributes of colleges and schools of pharmacy in the United States. Am J Pharm Educ. 2009;73(5):Article 96.

4. Regional Offices. Federal Trade Commission. https:// www.ftc.gov/about-ftc/bureaus-offices/regional-offices. Accessed February 26, 2021.

5. PCAT and Other Tests. Pharmacy College Application Service website. https:/www.pharmcas.org/school-directory/explore-andcompare/pcat-and-other-tests. Accessed February 26, 2021.

6. Muratov E, Lewis M, Fourches D, Tropsha A, Cox WC. Computer-assisted decision support for student admissions based on their predicted academic performance. Am J Pharm Educ. 2017; 81(3): Article 46.

7. Dell KA, Wantuch GA. Predicting success in pharmaceutical calculations. Curr Pharm Teach Learn. 2019;11(10):972-978. 8. Novovic J, Charrois TL, Cor MK, Hall JJ. Admissions processes in North American pharmacy schools: to what extent are characteristics of practice success measured? Curr Pharm Teach Learn. 2018;10(12):1550-1564.

9. McDonough SLK, Spivey CA, Chisholm-Burns MA, Williams JS, Phelps SJ. Examination of factors relating to student performance on the Pharmacy Curriculum Outcomes Assessment. Am J Pharm Educ. 2019;83(2):Article 6516

10. Hein B, Messinger NJ, Penm J, Wigle PR, Buring SM. Correlation of the Pharmacy Curriculum Outcomes Assessment and selected pre-pharmacy and pharmacy performance variables. $\mathrm{Am} \mathrm{J}$ Pharm Educ. 2019;83(3):Article 6579.

11. Gillette C, Rudolph M, Rockich-Winston N, et al. Predictors of student performance on the Pharmacy Curriculum Outcomes Assessment at a new school of pharmacy using admissions and demographic data. Curr Pharm Teach Learn. 2017;9(1):84-89. 12. Ferrante AB, Lambert J, Leggas M, Black EP. Predicting student success using in-program monitoring. Am J Pharm Educ. 2017;81(6): Article 111.

13. McLaughlin JE, Khanova J, Scolaro K, Rodgers PT, Cox WC. Limited predictive utility of admissions scores and objective structured clinical examinations for APPE performance. Am J Pharm Educ. 2015;79(6):Article 84. 


\section{American Journal of Pharmaceutical Education 2021; 85 (3) Article 8179.}

14. Heldenbrand SD, Dayer LE, Martin BC, et al. APPE evaluations are positively associated with MMI, pre-pharmacy GPA and pharmacy GPA. Am J Pharm Educ. 2018;82(7):Article 6326.

15. Olson E. More law schools begin accepting GRE test results. The New York Times. August 10, 2017. https://www.nytimes.com/2017/ 08/10/business/dealbook/law-school-gre.html. Accessed February 26, 2021.

16. Randazzo S. Law schools say: please come, no LSAT required. The Wall Street Journal. December 7, 2017. https:/www.wsj.com/ articles/law-schools-say-please-come-no-lsat-required-1512556201. Accessed February 26, 2021.

17. Coogan D. GRE vs. LSAT: what prospective law students need to know. US News and World Report. March 27, 2017. https:// www.usnews.com/education/blogs/law-admissions-lowdown/ articles/2017-03-27/gre-vs-lsat-what-prospective-law-students-needto-know. Accessed February 26, 2021.

18. Strauss V. A record number of colleges drop SAT/ACT admissions requirement amid growing disenchantment with standardized tests. https://www.washingtonpost.com/education/ 2019/10/18/record-number-colleges-drop-satact-admissionsrequirement-amid-growing-disenchantment-with-standardized-tests/. Accessed February 26, 2021.

19. Kawika Smith v Regents of the University of California. No RG19046222, complaint filed December 10, 2019. http:// www.publiccounsel.org/tools/assets/files/1250.pdf. Accessed February 26, 2021. 